\title{
Experiencia en el manejo de la inestabilidad anterior de hombro con técnica de remplissage
}

\author{
Experience in treatment of anterior shoulder instability with remplissage technique
}

\author{
Jaime Villalobos Medélez, ${ }^{*}$ I Jacobo-Nájera, ${ }^{\ddagger}$ Juan Carlos Téllez-Ávila, ${ }^{\ddagger}$ \\ Alicia Villalobos-Rodríguez,§ Jonathan Rubén Hernández-Molina* \\ *Traumatólogo Ortopedista. Cirujano Articular del Hospital Ángeles Mocel. Profesor adjunto del Curso en Alta Especialidad \\ Artroscopia y Cirugía de Rodilla, Universidad La Salle México; ${ }^{\ddagger}$ Médico residente del Curso de Subespecialidad en \\ Artroscopia y Cirugía de Rodilla. Hospital Ángeles Mocel, Universidad La Salle México; § Traumatólogo Ortopedista. \\ Cirujano Articular Hospital Ángeles Mocel.
}

\section{Resumen}

\begin{abstract}
Introducción: La dislocación del hombro puede resultar en una variedad de lesiones en donde se ven involucrados los tejidos blandos y óseos de la articulación glenohumeral. Se ha descrito que la lesión de tejido blando más común es la lesión de Bankart. Caso clínico: Paciente masculino de 43 años que acude al Servicio de Urgencias para valoración. El día 18 de junio de 2020, al estar haciendo actividades de escritorio, realizó extensión, abducción con rotación externa de miembro torácico izquierdo, posterior a ello inició con cuadro de deformidad acompañado de dolor e incapacidad funcional del segmento torácico. Conclusiones: La cirugía de reparación de Bankart, más la técnica de remplissage disminuyó la tasa de falla del procedimiento quirúrgico, y propició mejores resultados en el paciente.
\end{abstract}

Palabras clave: Inestabilidad anterior de hombro, lesión de Bankart, lesión de Hill-Sachs, técnica de remplissage.

\begin{abstract}
Introduction: Shoulder dislocation can result in a variety of injuries involving the soft and bony tissues of the glenohumeral joint. The most common soft tissue lesion has been described as the Bankart injury. Case report: A 43-year-old male patient who came to the emergency department for evaluation. On June 18, 2020, while engaged in desk activities, performed extension, abduction with external rotation of the left thoracic limb, after that, he developed deformity accompanied by pain, besides functional disability of the thoracic segment. Conclusions: Bankart repair surgery plus the remplissage technique decreased the failure rate of the surgical procedure, and led to better patient outcomes.
\end{abstract}

Keywords: Anterior shoulder instability, Bankart injury, Hill-Sachs injury, remplissage technique.

\section{Introducción}

La dislocación del hombro puede resultar en una variedad de lesiones en donde se ven involucrados los tejidos blandos y óseos de la articulación glenohumeral. Se ha descrito que la lesión de tejido blando más común es un desprendimiento del labrum del borde glenoideo, conocida como lesión de Bankart. ${ }^{1}$

Así como se puede presentar una fractura por compresión posterolateral de la cabeza humeral, conocida como lesión de Hill-Sachs, el cual es un hallazgo común asociado con la inestabilidad anterior del hombro, la cual se encuentra presente en aproximadamente $47 \%$ de las luxaciones glenohumerales anteriores por primera vez y en $90 \%$ en los casos recurrentes. ${ }^{2}$

Se ha observado que la tasa de recurrencia, después de un primer episodio de inestabilidad anterior del hombro es de $50 \%$, y $25 \%$ de los pacientes se someten a cirugía para estabilización del hombro. ${ }^{3}$
Correspondencia:

Dr. Jonathan Rubén Hernández-Molina

Gob. Ignacio Esteva No. 107. Cons 02 PB,

Col. San Miguel Chapultepec, 11850,

Alcaldía Miguel Hidalgo, CDMX

E-mail: jonyhm@ @otmail.com
Recibido: 20-03-2021. Aceptado: 13-04-2021.

Citar como: Villalobos MJ, Jacobo-Nájera I, Téllez-Ávila JC, VillalobosRodríguez A, Hernández-Molina JR. Experiencia en el manejo de la inestabilidad anterior de hombro con técnica de remplissage. Orthotips. 2021; 17 (2): 108-111. https://dx.doi.org/10.35366/99905 
El mecanismo más común de luxación anterior traumática del hombro ocurre con una fuerza indirecta sobre el brazo en abducción y rotación externa, la cabeza humeral gira externamente en relación con la glenoides mientras se traslada en sentido anterior. Se describe que las restricciones glenohumerales estáticas (cápsula, ligamentos, labrum) se estiran o desgarran con una mayor traslación anterior, resultando en dislocación de la cabeza humeral. ${ }^{4}$

Por otro lado, la cara posterosuperolateral de la cabeza humeral impacta sobre la cara anterior del borde glenoideo y puede crear la lesión de Hill-Sachs y/o una lesión ósea de Bankart. ${ }^{4}$

Las lesiones activas del tipo Hill-Sachs provocan inestabilidad recurrente y de igual manera una alta tasa de fracaso cuando se tratan sólo con reparación artroscópica de Bankart. ${ }^{5}$

\section{Presentación del caso}

Se presentó un paciente masculino de 43 años, comerciante, que no presentaba antecedentes personales ni patológicos de importancia; sin embargo, dentro de los antecedentes traumáticos describió luxaciones glenohumerales de repetición, con un primer evento hace tres años (año 2017) al estar

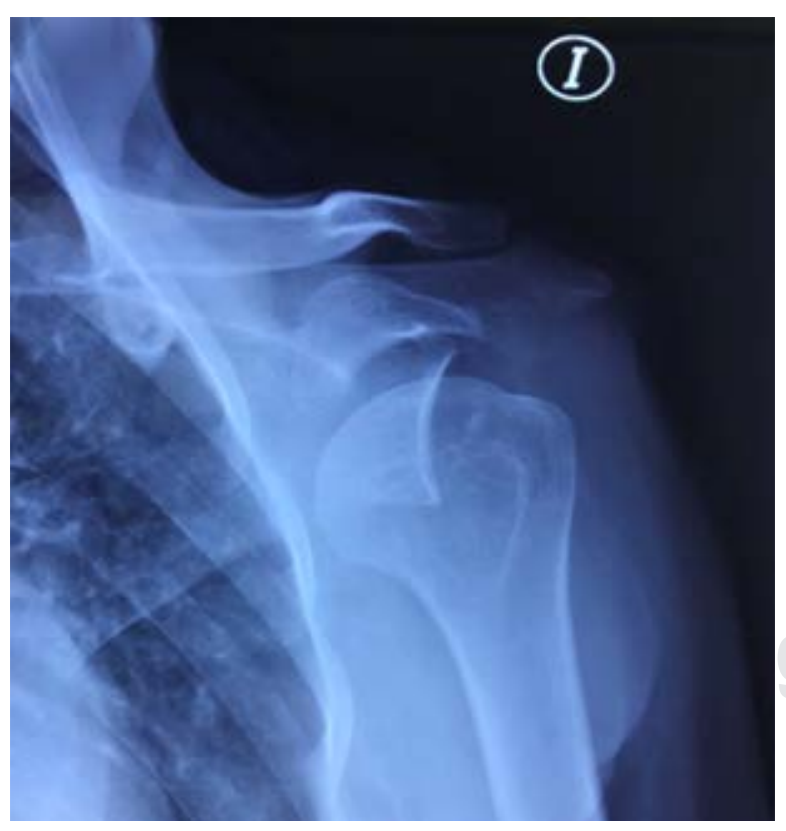

Figura 1: Radiografía simple de hombro izquierdo, proyección anteroposterior (antes de procedimiento quirúrgico). Se aprecia luxación glenohumeral.

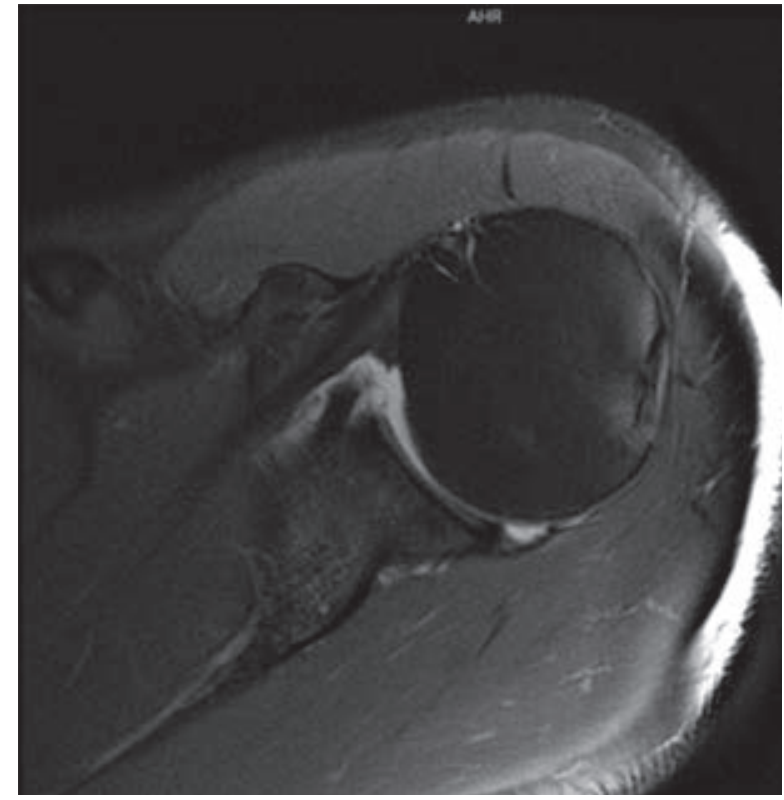

Figura 2: Resonancia magnética simple de hombro izquierdo, corte axial (antes de procedimiento quirúrgico). Se aprecia lesión de HillSachs.

descendiendo de unas escaleras realizó extensión abducción y rotación externa de torácico izquierdo, la cual tuvo reducción instantánea, sin manejo posterior al mismo, y otro evento hace un año (año 2019), posterior de realizar nueva extensión y rotación externa, ésta requirió de reducción bajo sedación, inmovilización y tres semanas posterior inició con rehabilitación.

Padecimiento actual: paciente que acude al Servicio de Urgencias para valoración ya que, el día 18 de junio de 2020, al estar haciendo actividades de escritorio, realizó extensión, abducción con rotación externa de miembro torácico izquierdo, posterior a ello inició con cuadro de deformidad acompañado de dolor e incapacidad funcional del segmento torácico.

Exploración física: los signos vitales se reportaron dentro de rangos de referencia, tenía peso de $90 \mathrm{~kg}$, talla de $210 \mathrm{~cm}$, índice de masa corporal de $20.4 \mathrm{~kg} / \mathrm{m}^{2}$.

En el área de urgencias se encontró al paciente con facies de dolor, con deformidad de segmento torácico izquierdo, charretera positiva, incapacidad para realizar arcos de movilidad a nivel de hombro, extensión de $30^{\circ}$, abducción de $20^{\circ}$, flexión de $10^{\circ}$, rotación interna de $15^{\circ}$, rotación externa de $10^{\circ}$, todas dolorosas, a nivel de codo con deflexión de $130^{\circ}$, y 
extensión de $0^{\circ}$, pulsos distales presentes sin compromiso neurovascular distal.

Laboratorios: se reportó una $\mathrm{Hb}$ de $14.5 \mathrm{~g} / \mathrm{dl}$, plaquetas $300,000 / \mathrm{mm}^{3}$, leucocitos $33,300 / \mathrm{mm}^{3}$, glucosa $88 \mathrm{mg} / \mathrm{dl}$, urea $14 \mathrm{mg} / \mathrm{dl}$, creatinina $0.86 \mathrm{mg} /$ dl, colesterol $150 \mathrm{mg} / \mathrm{dl}$, triglicéridos $110 \mathrm{mg} / \mathrm{dl}$, TP $14.4 \mathrm{~s}$, TPT $37.2 \mathrm{~s}$, INR 1.03.

Imagen: se realizó una radiografía con proyección anteroposterior (Figura 1), y una resonancia magnética simple de hombro izquierdo (Figuras 2 y 3) y se realizó el diagnóstico de luxación glenohumeral, inestabilidad anterior de hombro, lesión de Bankart y lesión de Hill-Sachs.

Plan: posterior al diagnóstico, se implementó protocolo preoperatorio y se realizó artroscopia de hombro izquierdo con reparación de Bankart y remplissage (Figura 4).

\section{Discusión}

Este paciente presentó recurrencia de inestabilidad del hombro por luxación glenohumeral, que indicaba una cronicidad importante en el mismo. Se puede describir que la inestabilidad recurrente del hombro puede deberse a un fallo en la cicatrización de la lesión inicial del tejido blando.

Pese a que la presencia de una lesión de HillSachs aumenta el riesgo de inestabilidad recurrente,

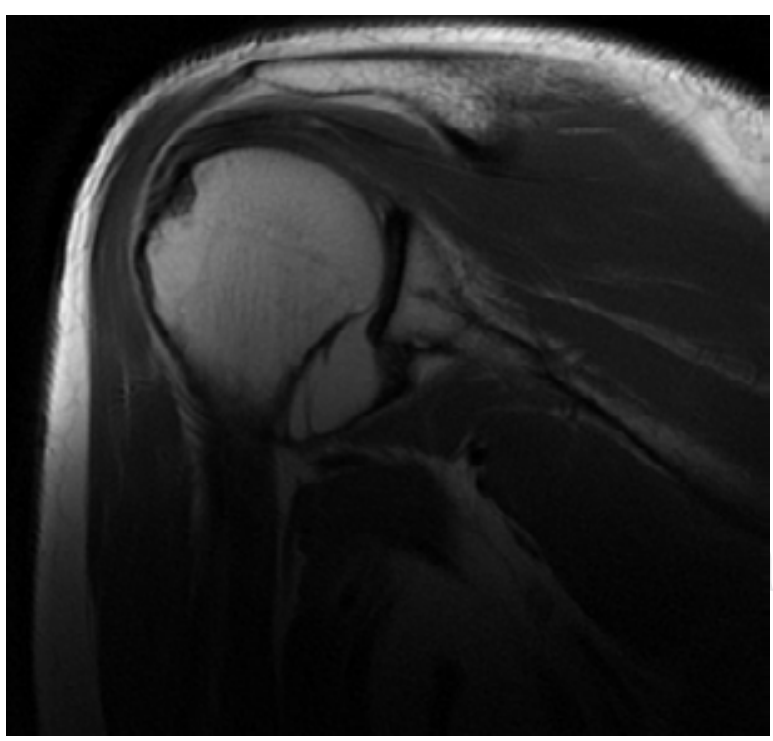

Figura 3: Resonancia magnética simple de hombro izquierdo, corte coronal (antes de procedimiento quirúrgico). Se aprecia lesión de HillSachs.

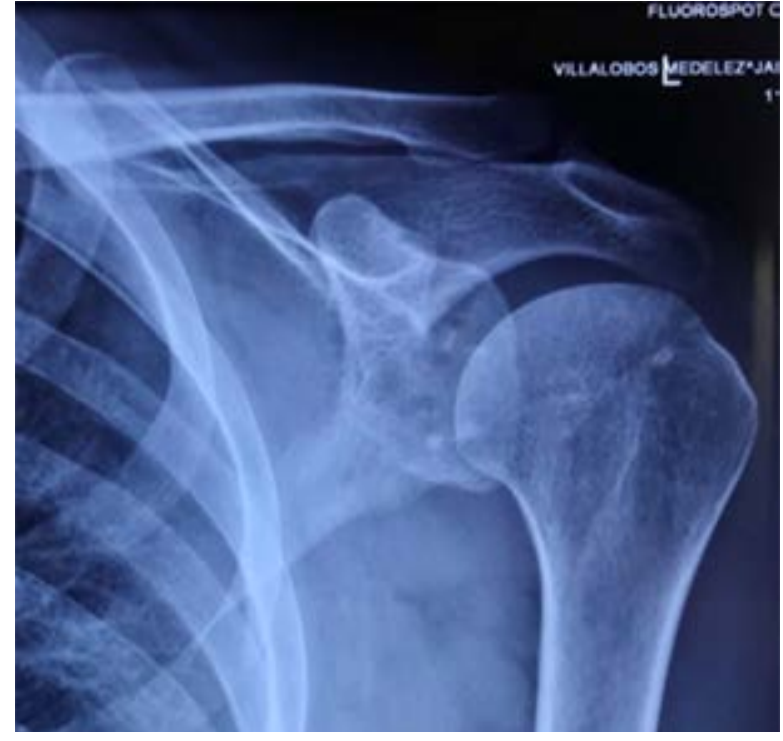

Figura 4: Radiografía simple de hombro izquierdo proyección anteroposterior (posterior a procedimiento quirúrgico). Se aprecia corrección de luxación glenohumeral.

es la lesión la que tiene un compromiso con el borde glenoideo en abducción y rotación externa, por lo cual requiere mayor atención. ${ }^{6}$

En las imágenes tomadas antes del procedimiento quirúrgico se observa, en la primera radiografía simple de hombro izquierdo en proyección anteroposterior, una luxación de la articulación glenohumeral, mientras que en la resonancia magnética simple (cortes axial y coronal), se detecta una lesión de Hill-Sachs y una lesión de Bankart, las cuales de acuerdo con la literatura son característica en los pacientes con luxación glenohumeral e inestabilidad anterior de hombro.

Los pacientes que presentan lesiones de HillSachs, después de una luxación anterior de la articulación glenohumeral, tienen un mayor riesgo de inestabilidad recurrente y fracaso de la cirugía de estabilización de tejidos blandos. ${ }^{7}$

La técnica de reincorporación (Remplissage) permite tratar pacientes con defectos humerales como las lesiones de Hill-Sachs grandes, se asocia con la reparación capsulolabral anterior y consiste en una plicatura del infraespinoso sobre el defecto humeral. ${ }^{8}$ En sí, la reparación artroscópica de Bankart combinada con la reincorporación de Hill-Sachs puede restaurar la estabilidad del hombro sin un deterioro significativo de la función de éste, en pacientes con lesiones de Hill-Sachs. ${ }^{9}$ 
En un estudio de cohorte retrospectivo de pacientes tratados con reparación artroscópica de Bankart con o sin reincorporación se concluyó que, en comparación con la reparación aislada de Bankart. Dicha reparación de Bankart, más la técnica de reincorporación, fue una opción superior para los pacientes con inestabilidad recurrente con grandes lesiones de Hill-Sachs, proporcionando una disminución de las tasas de falla y una mejora en las puntuaciones de los resultados. ${ }^{10}$

Se reportó en el citado paciente un resultado muy favorable posterior a la artroscopia de hombro con reparación de Bankart y remplissage, ya que se logró recuperar el déficit que presentaba el paciente al momento de evaluar los arcos de movilidad (extensión, abducción, flexión, rotación interna, rotación externa), así como la disminución del dolor.

\section{Conclusiones}

Las lesiones características de un paciente con inestabilidad anterior de hombro por luxación glenohumeral son la lesión de Bankart y la lesión de Hill-Sachs, señaladas en el caso de este paciente.

Se describió que la lesión de Hill-Sachs se encuentra presente en $90 \%$ de los casos con recurrencia. Pese a que en el presente reporte no se determina el porcentaje por la cantidad de pacientes en estudio, se corrobora que en este caso la recurrencia sí estuvo presente.

Los estudios de imagen permiten una evaluación más integral y precisa para determinar el diagnóstico.

A pesar de que se refiere que en los casos con lesiones de Hill-Sachs, después de una luxación anterior de la articulación glenohumeral se puede presentar un fracaso de la cirugía de estabilización de tejidos blandos, este reporte no fue el ejemplo, ya que el paciente presentó resultados muy satisfactorios.
La cirugía de reparación de Bankart más la técnica de remplissage disminuyó la tasa de falla del procedimiento quirúrgico, y propició mejores resultados en el paciente.

\section{Referencias}

1. Fountzoulas K, Hassan S, Khoriati AA, Chiang $\mathrm{CH}$, Little N, Patel V. Arthroscopic stabilisation for shoulder instability. J Clin Orthop Trauma. 2020; 11 (Suppl 3): S402-S411.

2. Abouelsoud MM, Abdelrahman AA. Recurrent anterior shoulder dislocation with engaging Hill-Sachs defect: remplissage or Latarjet? Eur Orthop Traumatol 2015; 6 (3): 151-156.

3. Bah A, Lateur GM, Kouevidjin BT, Bassinga JYS, Issa M, Jaafar A, et al. Chronic anterior shoulder instability with significant Hill-Sachs lesion: Arthroscopic Bankart with remplissage versus open Latarjet procedure. Orthop Traumatol Surg Res. 2018; 104 (1): 17-22.

4. Patel R, Amin N, Lynch T, Miniaci A. Management of bone loss in glenohumeral instability. Orthop Clin North Am. 2014; 45 (4): 523-539.

5. Buza J, lyengar J, Anakwenze O, Ahmad C, Levine W. Arthroscopic Hill-Sachs remplissage: a systematic review. J Bone Joint Surg Am. 2014; 96 (7): 549-555.

6. Garcia G, Wu H, Liu J, Huffman R, Kelly J. Outcomes of the remplissage procedure and its effects on return to sports: average 5-year follow-up. Am J Sports Med. 2016; 44 (5): 1124-1130.

7. Camp C, Dahm D, Krych A. Arthroscopic remplissage for engaging Hill-Sachs lesions in patients with anterior shoulder instability. Arthrosc Tech. 2015; 4 (5): 499-502.

8. Ruiz M, Díaz J, Ruíz R, Cuellar A, Valencia M. Técnica de remplissage para defectos humerales grandes. Un estudio a medio plazo de cohortes emparejadas. Rev Esp Artrosc Cir Articul. 2014; 21 (2): 85-89.

9. Zhu Y, Lu Y, Zhang J, Shen J, Jiang C. Arthroscopic Bankart repair combined with remplissage technique for the treatment of anterior shoulder instability with engaging Hill-Sachs lesion: a report of 49 cases with a minimum 2-year follow-up. Am J Sports Med. 2011; 39 (8): 1640-1647.

10. Garcia GH, Park MJ, Zhang C, Kelly JD 4th, Huffman GR. Large Hill-Sachs lesion: a comparative study of patients treated with arthroscopic Bankart repair with or without remplissage. HSS J. 2015; 11 (2): 98-103.

\section{Conflicto de intereses}

No se tiene ningún conflicto de intereses por parte del autor o sus colaboradores. 